\title{
Fibrovascular polyps of the esophagus
}

Parvez K. Sultan, MD, Bryan F. Meyers, MD, G. Alexander Patterson, MD, and Joel D. Cooper, MD, St Louis, Mo

$\mathrm{F}$ librovascular polyps are uncommon benign tumors of the esophagus. Synonyms include fibroma, fibrolipoma, pedunculated lipoma, and fibroepithelial polyp. Eighty percent arise just distal to the cricopharyngeus and can then progress to either an intramural or an intraluminal tumor, with some having both components. ${ }^{1}$ We report the cases of 2 patients who underwent resections for both types of polyps.

\section{Clinical Summary}

PATIENT 1. A 38-year-old man had, in recent months, a cough and mild stridor. A chest computed tomographic scan revealed a posterior

From the Division of Cardiothoracic Surgery, Washington University School of Medicine, St Louis, Mo.

Received for publication March 25, 2005; revisions received May 2, 2005; accepted for publication May 20, 2005.

Address for reprints: Joel D. Cooper, MD, Division of Cardiothoracic Surgery, 3108 Queeny Tower, One Barnes-Jewish Hospital Plaza, St Louis, MO 63110 (E-mail: joel.cooper@uphs.upenn.edu).

J Thorac Cardiovasc Surg 2005;130:1709-10

$0022-5223 / \$ 30.00$

Copyright @ 2005 by The American Association for Thoracic Surgery doi:10.1016/j.jtcvs.2005.05.043 mediastinal mass, with displacement of the esophagus to the left. Endoscopy revealed an intramural mass and tracheal narrowing at the thoracic inlet. In 1988, a routine chest radiogram first indicated deviation of the trachea. A right transverse cervical incision ensued, and after identification of the recurrent nerve, a myotomy just below the cricopharyngeus revealed a glistening, cylindrical, white mass that extended $13 \mathrm{~cm}$ inferiorly. Through the cervical approach, with minimal extension of the myotomy, this intramural mass was totally removed, without incurring a mucosal rent. The myotomy site was closed with interrupted silk sutures, and the patient remains asymptomatic 4 years later.

PATIENT 2. A 58-year-old woman presented with dysphagia and occasional right-sided neck pain on swallowing. Barium studies revealed a large filling defect within a dilated esophagus (Figure 1, A). At the time of endoscopy, an intramural polyp was seen projecting intraluminally $4 \mathrm{~cm}$ above the hiatus (Figure $1, B$ ). A right posterolateral thoracotomy was made through the bed of the resected fifth rib, and after incision of the mediastinal pleura, the soft mass was readily palpable in the esophagus. A 2-cm myotomy was made above the azygos vein, and by means of blunt dissection, the intramural portion of the mass was freed inferiorly to its site of intraluminal protrusion. A circumferential incision of the mucosa around the perimeter of the polyp allowed its removal from within the esophageal lumen. The polyp was then totally extirpated by means of further blunt dissection

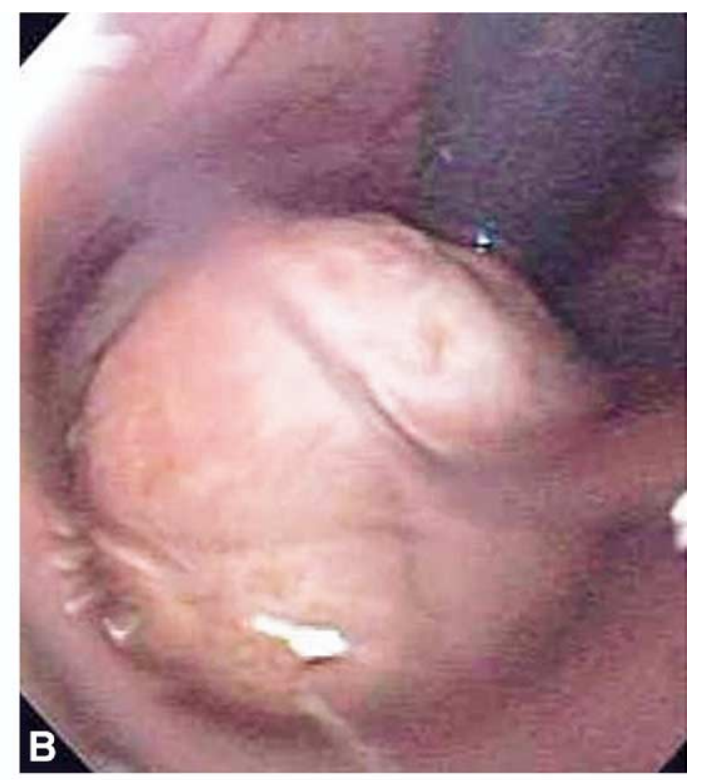



Figure 1. A. An intramural polyp. B, Intraluminal protrusion of polyp. 


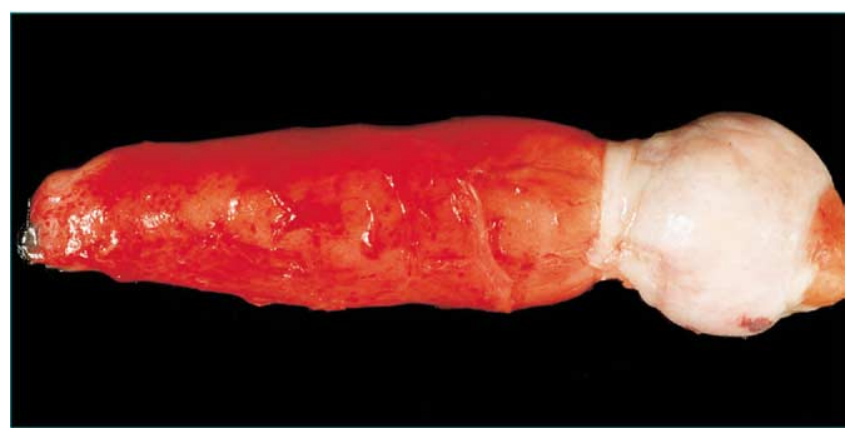

Figure 2. Gross pathology, patient 2.

superiorly in the submucosa (Figure 2). Redundant mucosa resulting from the intraluminal protrusion of the lesion at the site of polyp extraction was resected with a TA30 vascular stapler (Ethicon, Cincinnati, Ohio). The myotomies were closed with interrupted 4-0 silk sutures.

\section{Discussion}

In 1922, Vincent was the first to surgically remove a fibrovascular polyp, and by 1957, only 6 cases were reported from the Mayo Clinic. In the interim, case reports have been more frequently forthcoming.

Both the intraluminal and the intramural polyps arise from the lamina propria and can be smooth, lobulated, or multilobulated. The mucus membrane of squamous epithelium is usually intact over both varieties of polyps, but mucosal ulceration can occur as a result of food intake or peptic digestion. Microscopically, loose fibrovascular tissue with myomatous and fatty changes is seen in varying degrees.

The origin in the proximal esophagus permits caudal extension of the polyps through the propulsive act of swallowing. Death from regurgitation of a pedunculated intraluminal polyp has been reported. ${ }^{2}$ Postmortem examination revealed a larynx blocked by a polypoid mass. Regurgitation of a mass into the mouth associated with acute respiratory distress has been reported. Some patients who become aware of a mass in their hypopharynx obtain relief by swallowing or manually reducing the polyp.

Dysphagia, the most common symptom of both types of fibrovascular polyps, can first occur only when the lesion has become markedly enlarged. Totten and colleagues ${ }^{3}$ categorized the gastrointestinal symptomatology resulting from such masses, which included dysphagia, regurgitation, vomiting, anorexia, and hiccups. Respiratory symptoms of cough, dyspnea, stridor, wheezing, recurrent episodes of aspiration, pneumonia, and choking spells have been reported. Pain, if present, was manifested by substernal epigastric distress, frequent sore throats, and the sensation of a mass in the throat.

Barium studies and an esophagoscopy are necessary to establish the diagnosis. ${ }^{4}$ The polyps might not be visualized during endoscopy because of their intramural location, but a barium swallow usually demonstrates a significant filling defect within the widened esophagus suggestive of an intraluminal mass.

Although small lesions can be removed by means of endoscopy, the presence of a pedicle, which can be highly vascular, should mandate either a cervical incision or a thoracotomy for resection. ${ }^{5}$ It should be emphasized that although some polyps can be intraluminal, totally intramural lesions can be freed up by using a small myotomy, with subsequent dissection within the wall of the esophagus through a cervical incision.

\section{References}

1. Bernatz PE, South JL, Ellis FH, Anderson HA. Benign pedunculated intraluminal tumors of the esophagus. J Thorac Surg. 1958;35:503-51.

2. Allen MS, Talbot WH. Sudden death due to regurgitation of a pedunculated esophageal lipoma. Ann Thorac Surg. 1957;54:756-9.

3. Totten RS, Stout AP, Humphries GH, Moon RL. Benign tumors and cysts of the esophagus. J Thorac Surg. 1953;25:606-22.

4. Choong CF, Meyers BF. Benign esophageal tumors. Semin Thorac Cardiovasc Surg. 2003;15(1):3-8.

5. Lolley D, Razzuk MA, Urschel HC. Giant fibrovascular polyps of the esophagus. Ann Thorac Surg. 1976;22:382-4. 